\title{
Correction to: The relationship between ventilator-associated pneumonia and chronic obstructive pulmonary disease: What is the current evidence?
}

\author{
Despoina Koulenti ${ }^{1,2,3} \cdot$ Francesca Romana Parisella $^{1}$ (D) Elena X $\mathbf{u}^{1} \cdot$ Jeffrey Lipman ${ }^{1,2,4} \cdot$ Jordi Rello ${ }^{5}$
}

Published online: 28 February 2019

(C) Springer-Verlag GmbH Germany, part of Springer Nature 2019

\section{Correction to: European Journal of Clinical Microbiology \& Infectious Diseases https://doi.org/10.1007/s10096-019-03486-2}

Unfortunately, the Acknowledgements section below was not included in the original version of the article.

Acknowledgements We would like to express our very great appreciation to Mr. Lars Eriksson, The University of Queensland, UQ Library, Herston Qld 4006, Australia, for his valuable assistance with literature search.

Publisher's note Springer Nature remains neutral with regard to jurisdictional claims in published maps and institutional affiliations.

The online version of the original article can be found at https://doi.org/ 10.1007/s10096-019-03486-2

Francesca Romana Parisella

f.parisella@uqconnect.edu.au

1 UQ Centre for Clinical Research, Faculty of Medicine, The University of Queensland, Brisbane, Australia

2 Royal Brisbane Clinical Unit, Faculty of Medicine, The University of Queensland, Brisbane, Australia

3 2nd Critical Care Department, Attikon University Hospital, Athens, Greece

4 Department of Intensive Care Medicine, Royal Brisbane and Women's Hospital, Brisbane, Australia

5 Vall d'Hebron Institute of Research (VHIR) \& CIBERES, Instituto Salud Carlos III, Barcelona, Spain 